REVISTA ARA N9. VOlUME 9. PRIMAVERA+VERÃO 2020 • GRUPO MUSEU/PATRIMÔNIO FAU-USP

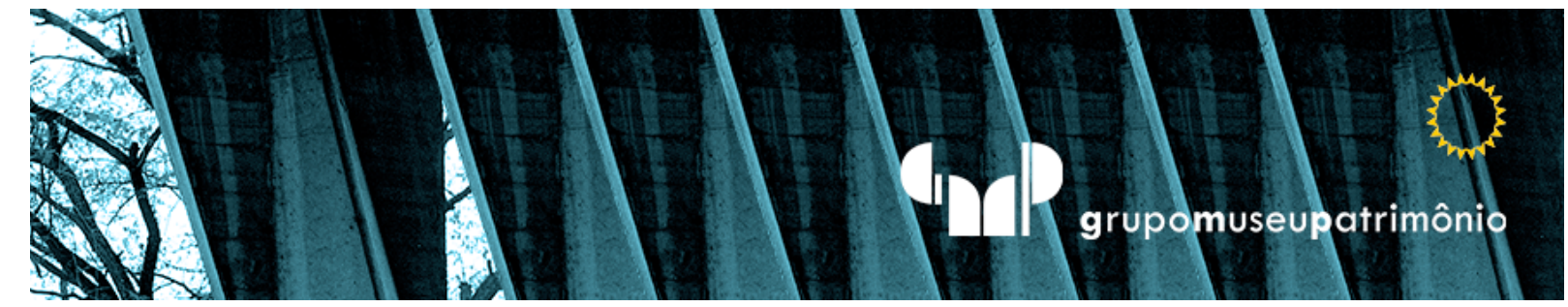

\title{
Cartografias do levante ${ }^{1}$
}

\author{
Cartographies of the levant
}

\section{Cartografías del levante}

\author{
Márcia Sandoval Gregori \\ Pós-doutoranda na FAU-USP, doutora pela FAU-Mackenzie \\ marciagregori@hotmail.com
}

\footnotetext{
${ }^{1}$ Este artigo insere-se em processo de pesquisa de pós-doutorado realizada junto ao Departamento de História e Estética do Projeto da Faculdade de Arquitetura e Urbanismo da Universidade de São Paulo, sob a supervisão da Profa. Titular Sênior Maria Cecília França Lourenço. As imagens aqui apresentadas foram realizadas pela autora entre fevereiro e março de 2020, antes da quarentena de prevenção ao coronavírus a que ficamos sujeitos definitivamente a partir do dia 23 de março do mesmo ano.
} 


\section{Resumo}

O artigo tem como objetivo refletir sobre a prática cartográfica como possibilidade de ação política revolucionária e insurgente. Entende-se a cartografia tradicional e seus mapas como representações dominantes, dispositivos engendrados por relações de poder. A cartografia do levante, por sua vez, é compreendida como uma prática de desativação desses mecanismos de controle e captura para transformá-los em contra-dispositivos, em atuação transformadora, profanadora. A partir de imagens feitas pela pesquisadora busca-se analisar como essa fazer pode se inserir em cartografias do levante.

\section{Palavras-chave}

Cartografia. Representação. Levante. Dispositivo. Contra-dispositivo.

\section{Resumen}

El artículo tiene como objetivo reflexionar sobre la práctica cartográfica como una posibilidad de acción política revolucionaria e insurgente. La cartografía tradicional y sus mapas se entienden como representaciones dominantes, dispositivos engendrados por las relaciones de poder. La cartografía de la sublevación, a su vez, se entiende como una práctica de desactivar estos mecanismos de control y captura para transformarlos en contra-dispositivos, en un desempeño transformador, profano. En base a las imágenes tomadas por el investigador, se busca analizar cómo se puede insertar esta acción en la cartografía de la sublevación.

\section{Palabras-clave}

Cartografía. Representación. Sublevación. Dispositivo. Contra-dispositivo.

\section{Abstract}

This article aims to reflect on cartographic practice as a possibility for revolutionary and insurgent political action. Traditional cartography and its maps are understood as dominant representations, devices engendered by power relations. The cartography of the uprising, in turn, is understood as a practice of deactivating these mechanisms of control and capture in order to transform them into counter-devices, in a transformative, profane performance. Based on images taken by the researcher, it is sought to analyze how this action can be inserted in cartography of the uprising.

\section{Keywords}

Cartography. Representation. Uprising. Device. Counter-device. 
A vida de cada um é única. O nascimento, a morte, o desejo, o amor, a relação com o tempo, com os elementos, com as formas vivas e com as formas inanimadas são, para um olhar depurado, novos, inesperados, miraculosos.

Felix Guattari (1992)

1.

ia claro em São Paulo. Diante de um semáforo luminoso vermelho, em um cruzamento no centro da cidade, automóveis param. Pela rua transversal, vindo da esquerda dos motoristas, um homem vestido com roupas puídas de uma tonalidade marrom-café, resultado da mistura de gordura, suor, terra e sujeira de dias, semanas ou meses de vida na rua, caminha vagaroso em direção à faixa de pedestres. Traz nas mãos alguns objetos amarrados por um fio: reminiscências de um lugar habitado? Simulacro de uma casa inexistente, ora invisível, diluída nas ruas e calçadas da anônima cidade? 
Personificações das individualidades de seus motoristas, alguns dos veículos da primeira fila avançam sobre a faixa a cada pequena acelerada, ansiosos por continuar sua ida apressada a algum lugar da cidade que não pode parar, como se estivessem em uma pista de atletismo esperando alertas pelo disparo da largada. Mas o sinal permanece vermelho, e o homem segue lento e constante, até que começa a cruzar a via. Quando está no primeiro terço da travessia, o sinal fica verde para os carros. Ainda silenciosos, os motoristas pressionam, aceleram e invadem mais alguns centímetros da faixa, reafirmando sua impaciência. As máquinas resfolegam e rosnam como animais nervosos.

O homem inspira e sutilmente retarda o passo. Aproveita a oportunidade e recua um pouco, avança mais um tanto, retrocede e segue, até parar no meio da via. Faz gestos amplos, dançantes, derruba e cata vagarosamente seus objetos e encara os espectadores com um misto de ironia, sarcasmo e agressividade. O ar, suspenso na incômoda incerteza, faz os segundos parecerem horas. Ninguém ousa prosseguir ou se manifestar diante do imprevisto espetáculo. É preciso ver, com forçosa atenção e desconforto, a miséria que desfila, teimosamente demorada, diante da tela emoldurada dos para-brisas, nas inevitáveis paradas dos automóveis pelos cruzamentos da urbe.

\section{INTRODUÇÃO}

O objetivo deste artigo é refletir sobre a prática de uma cartografia do levante ${ }^{2}$ e usar experiências fotográficas realizadas como exemplo de ato insurrecto e

\footnotetext{
${ }^{2}$ Para o filósofo e curador Georges Didi-Huberman, um levante pode ser tanto uma insurgência explícita, um ato de revolta, quanto um gesto clandestino, desejo de resistência que sobrevive em imagens àquele que o praticou. Em português o termo também remete ao processo arqueológico. Neste caso a recuperação de objetos, imagens e informações que, por motivos vários, tenham sido negligenciadas ou negadas por narrativas consolidadas e hegemônicas.
} 
elemento integrante de cartografias. $\mathrm{O}$ artigo visa tratar da elaboração de uma cartografia insurgente, que capte e sinalize também os gestos insubordinados, capaz de transformar a linguagem de composição dos mapas num aparato que subverta a lógica de controle e dominação intrínseca ao funcionamento do dispositivo, ou seja, num contra-dispositivo (AGAMBEN, 2009) ${ }^{3}$.

Se "[...] as ações humanas produzem espaço" (BARBOSA, 2014, p. 18), a cartografia pode ser um instrumento para a concepção de outras formas espaciais, dentro de um campo que inclua as artes, os saberes tradicionais, os sonhos e desejos, e estimule o pensamento crítico, a imaginação e a ação política. O mapa deve, então, ser pensado como um texto aberto, nãototalizante, registro de movimentos, reflexão e memória e não como objeto acabado, morto, ou como espelho fiel de uma realidade mutante.

Ao representar a realidade, as práticas cartográficas operam um deslocamento dimensional e interpretativo. Configuram imagens que interpretam a realidade segundo culturas, interesses e desejos que variam de acordo com a época, lugar e grupos praticantes. Além daquilo que deixam ver, mapas podem revelar, a um olhar mais atento, valores, hierarquias, concepções de mundo, apagamentos, vazios e esquecimentos, relacionando-se ao tema proposto.

Muitos mapas serviram, historicamente, como dispositivos para conquistar territórios, subjugar populações e submeter coletividades diversas a dominações espaço-culturais de grupos hegemônicos. Apoiados em "discursos de verdade ${ }^{\prime 4}$, foram naturalizados como se fossem espelhos fiéis da realidade.

\footnotetext{
${ }^{3}$ O filósofo Giorgio Agamben (2009) define dispositivo a partir do termo de Michel Foucault. Para o filósofo italiano, dispositivo é qualquer coisa capaz de "capturar, orientar, determinar, interceptar, modelar, controlar e assegurar gestos, condutas, opiniões e discursos" (p. 40). Organizados em rede, os dispositivos inscrevem-se no jogo de poder e resultam das relações de poder e de saber dominantes.

${ }^{4}$ Segundo Michel Foucault (2010) os "discursos de verdade", produzidos por relações de poder, apoiam-se em suposta objetividade técnica e racionalidade, são investidos de um sentido de veracidade irrefutável e ocultam os interesses daqueles que, ao proferir e chancelar tal discurso, dele se beneficiam relegando outras narrativas ao esquecimento. São formulados e reafirmados pelas instituições, pelas classes dominantes e representantes do poder constituído.
} 
Um claro exemplo de hegemonia cultural naturalizada é a tradicional disposição do mapa-múndi em praticamente todos os Atlas e publicações. 0 Norte - no qual estão os países mais desenvolvidos - é frequentemente voltado para cima, enquanto o sul - majoritariamente formado por nações subdesenvolvidas ou em desenvolvimento - fica representado em sugestivo e significativo lugar abaixo.

Exemplo de desnaturalização dessa narrativa é o mapa "América Invertida", 1943, do artista uruguaio Joaquín Torres García. Ao apontar o polo sul para cima e representar navios, peixes, sol, lua e estrelas neste sentido inverso ao costumeiro, o autor desloca e se insurge contra a leitura dominante com uma nova representação que ultrapassa o desenho e se desdobra em outros significados sobre desigualdades globais, estruturas sociais, relações sociais e culturais.

Após a Segunda Guerra Mundial (1939-45), o urbanismo de viés racionalista e funcionalista, existente desde o início daquele século, se fortaleceu e adquiriu maior importância. Fundado em discurso técnico e racional, esse urbanismo dividiu cidades em zonas com funções específicas, criou os alegados e festejados "modernos" sistemas de tráfego, baseados, sobretudo, no deslocamento por automóvel e em gigantescas obras e intervenções, e demoliu bairros e histórias inteiros ${ }^{5}$. O espaço seguia derrotado pela velocidade e pela urgência do capital em detrimento da territorialidade, das pessoas e da vida.

Nesse período, artistas, intelectuais e pensadores propuseram um deslocamento da prática cartográfica para um lugar de insubordinação, propondo novas práticas cartográficas. Desde então, tal abordagem crítica do

\footnotetext{
${ }^{5}$ Exemplo de urbanismo "modernizador" de viés racionalista e traços autoritários é o caso do plano diretor que o engenheiro e urbanista Robert Moses propôs para Nova York, com a construção de grandes obras viárias para organizar o tráfego da cidade e a consequente descaracterização e fragmentação de diversos territórios e histórias locais. Moses foi confrontado pela jornalista Jane Jacobs, que defendia as ruas ocupadas por pedestres e o sentido de comunidade nos bairros.
} 
espaço se faz cada vez mais presente e participante das produções artísticas atuais, entre as quais a arte urbana, arte pública, land art e site specific, entre outras (BARBOSA, 2014).

O esforço para romper com a falsa ideia de uma cartografia verdadeira e precisa salientava a práxis como meio de construção de uma vida urbana na qual a arte, a expressão e o pensamento crítico e criativo estivessem significativamente presentes no cotidiano, repensando e recolocando pesos e valores das atividades humanas.

Esses mapas rebeldes, engendrados em práticas não dominantes, contrárias à redução matemática e voltadas ao levantamento dos gestos e relações sociais, questionavam o modo de produção, o status quo e a cidade resultante de tal ordem. Buscavam representar espaços complexos, formados por materialidades e imaterialidades, frutos de ações humanas e por elas transformados em seu uso. Adquiriram traços psicológicos, subjetivos, e, assim, tridimensionalizaram o plano cartográfico tradicional inserindo-se em práticas atuantes no sentido oposto ao funcionamento do dispositivo forjado pelo e para o sistema.

\section{CARTOGRAFIA COMO DISPOSITIVO}

A cartografia é uma linguagem por meio da qual é possível registrar graficamente em um mapa um fenômeno como o descrito no início do artigo com ricos detalhes. As várias técnicas existentes e desenvolvidas em diferentes épocas possibilitaram a inscrição de dados em uma enorme variedade de mapas ao longo da história.

$\mathrm{Na}$ atualidade, programas de computador permitem o armazenamento de informações geometricamente situadas em pontos específicos do espaço 
demarcados por coordenadas precisas ${ }^{6}$. Em outros períodos, os registros cartográficos eram feitos sobre pedra, pergaminhos e, mais recentemente, sobre papel.

Vale lembrar, portanto, que ao descreverem as características morfológicas, censitárias e de infraestrutura nos pontos no território, tais notações podem ser insurgentes, mas também podem viabilizar controles rigorosos e personalizados, fenômeno que se observa cada vez mais intensamente com as novas tecnologias de localização, reconhecimento facial ou de voz, identificação digital, câmeras de vigilância, entre outras inovações técnicas que seduzem e capturam seus usuários, produzindo subjetivações ${ }^{7}$.

Segundo o geógrafo John Brian Harley, professor universitário e estudioso da cartografia, um mapa é uma representação gráfica bidimensional que responde a uma vontade de balizar o espaço, desejo que acompanha a humanidade desde eras remotas ${ }^{8}$. Seu objetivo é, ao substituir o espaço real por um analógico, facilitar a compreensão de objetos, fatos, conceitos e processos do mundo. Isso significa que ele está inserido um contexto e expressa os interesses e interpretações de quem o produz. Mapas descrevem a realidade. E descrever é narrar, interpretar. Mais do que um espelho fiel, eles são representações ${ }^{9}$, descrições "[...] do mundo em toda a sua diversidade cultural" (HARLEY, 1995, p. 9).

\footnotetext{
${ }^{6} \mathrm{~A}$ ideia do controle remete às categorias propostas por Guy Debord: o espaço estriado esquadrinhado geometricamente, dominado e controlado - em oposição ao espaço liso, - sem limites, aberto, orgânico.

${ }^{7}$ No filme Privacidade hackeada, os diretores Jehane Noujaim e Karim Amer mostram como mapeamentos do comportamento das pessoas, desde o tipo de consumo de bens até hábitos socioculturais foram cruciais para definir as eleições estadunidenses porque auxiliaram os estrategistas políticos a disparar fake news em massa para alvos mais vulneráveis e assim manipular a compreensão dos fatos.

${ }^{8}$ Segundo Harley, o primeiro mapa de que se tem notícia data de 6000 a.C. e foi descoberto na atual Turquia, no entanto, pinturas e gravações em rochas da África, América, Ásia e Europa já são estudadas como a pré-história da cartografia (HARLEY, 1995).

${ }^{9}$ Para o historiador Roger Chartier (1990) a representação é um instrumento de significação do mundo social, mediante apropriações e práticas coletivas. As diversas representações compõem discursos que se inserem em formações socioculturais. São, portanto, sempre matizados por
} 
Em outras palavras, mapas são formas de saber socialmente construídas, modos de compreensão do mundo baseados em linguagem gráfica e engendrados por contextos e técnicas específicos. Distantes de uma reprodução objetiva e precisa da realidade, resultam de práticas políticas e associam-se a conteúdos simbólicos, imaginários; interpretam o mundo. São, portanto, dinâmicos, contextuais e variam de acordo com o tempo e a cultura que os elaborou.

A partir do século XIX, na cultura europeia ocidental, mapas foram considerados marcos de uma evolução qualitativa da humanidade, o que resultou em estudos focados naqueles que apresentavam preocupações com a chamada linguagem científica, de viés matemático e supostamente objetivo, enquanto os que não indicassem tal orientação seguiram menos investigados ou não classificados como documentos cartográficos (HARLEY, 1995). Isso fez com que registros de outras culturas fossem obliterados, silenciados, e somente a partir da segunda metade do século XX tenham se tornado objeto de interesse investigativo nos círculos acadêmicos ocidentais.

Nos anos 1980, Harley (1995) examinou mapas como discursos de poder ${ }^{10}$, atos deliberados, articulações que sustentam práticas de vigilância e adaptações cognitivas conforme valores e crenças dominantes. Para o geógrafo esta operação "dessocializa" os territórios representados, apresentando-os como espaços socialmente vazios. Se o território for compreendido como um espaço social ${ }^{11}$, interligação de fluxos econômicos,

interesses e formações histórico-culturais. Não são, pois, retratos fiéis da realidade, mas processos de compreensão e construção do mundo por parte de diferentes grupos. São motivo de disputa e tensão e revelam lutas políticas pela legitimação de discursos e seus significados, ou seja, por poder.

${ }^{10}$ Discurso de poder remete à ideia dos discursos de verdade, formulada por Michel Foucault (2010).

${ }^{11}$ Espaço definido, em consonância com o entendimento de Pierre Bourdieu (2013) e de Milton Santos (2017), como imbricação de materialidades e imaterialidades. Possui dimensões não somente físicas, mas sociais e culturais e é essencialmente humano e político. Por conseguinte, trata-se de objeto de interesse investigativo enquanto instância de relações e práticas humanas, sociais, políticas, item indispensável para a condução e elaboração de políticas públicas democráticas e inclusivas. 
políticos, culturais e sociais, práticas de pessoas e grupos, materialidades nas quais as camadas históricas se apresentam e evidenciam fluxos passados e ações transformadoras do presente, uma representação que não dê conta dessa constituição sociocultural do espaço é, fatalmente, uma representação parcial, muitas vezes distorcida e humanamente vazia.

Em última análise, o procedimento de esvaziamento permite criar mapas desumanizados cujo objetivo primeiro é ser instrumento de vigilância e controle para a conquista e subjugo de territórios, evidenciando seus pontos de vulnerabilidade e apartando o espaço topográfico do espaço social. Neste sentido, muitos registros cartográficos podem ser considerados dispositivos, ou seja, aparatos que servem para controlar, capturar e ordenar discursos e ações humanas.

Com seus estudos, Harley e outros geógrafos dos anos $1990^{12}$ problematizaram a produção e o estudo da cartografia e abriram terreno para uma cartografia que se opõe aos modelos tradicionais de mapas, a chamada "cartografia crítica". Foram precedidos por artistas e filósofos que, desde as vanguardas do início do século $\mathrm{XX}$, questionaram a ordem dominante e procuraram explorar modelos alternativos de mapeamento (MESQUITA, 2013, p. 12), propondo contra-ações subversivas para cartografias de outra natureza que não aquelas voltados ao subjugo de populações, à conquista de territórios e outros propósitos dominadores e autoritários.

\section{CARTOGRAFIA COMO JOGO}

Grupo formado em 1957, os situacionistas ${ }^{13}$ denunciavam o caráter alienante de uma sociedade mercantilizada e consumista cujo modo de produção

\footnotetext{
${ }^{12}$ De acordo com André Mesquita (2013) entram neste rol Denis Wood, Denis Cosgrove, John Pickles, Jeremy Crampton e John Krygier.

${ }^{13}$ A Internacional Situacionista foi formada em 1957 e incluía artistas, intelectuais e teóricos, como Guy Debord, Asger Jorn, Raoul Vaneigem, Michèle Bernstein, Constant Nieuwenhuys e Asger Jorn, entre outros.
} 
engendrava cidades que materializavam em seu território o privilégio à produção, ao trabalho e ao consumo. Baseadas na ordenação vertical opressora e autoritária dos tempos e espaços humanos esvaziavam, assim, o sentido da vida social e individual das pessoas.

De origem marxista e anarquista, seus integrantes propunham uma prática urbana gerada a partir de situações cotidianas, pequenos atos subversivos associados à reflexão sobre os efeitos do ambiente nos atos e emoções humanos. Tratava-se de um método experimental a ser praticado permanente e cotidianamente que deveria tirar as pessoas da alienação e da acomodação para construir cidades nas quais a arte e a cultura teriam primazia sobre as matemáticas práticas ordenadoras, supostamente objetivas e racionais, dos poderes dominantes. Estas situações seriam geradas pela libertação do jogo, uma "[...] autonomia criativa, que supera a velha divisão entre o trabalho imposto e o ócio passivo" (MANIFESTO, 1960).

Fugir ao gesto repetitivo no espaço urbano, romper limites e libertar a humanidade da ordenação cotidiana do tempo produtivo era o eixo da proposta situacionista. Derivas, psicogeografias e desvios eram algumas das experiências criadas para fazer a crítica da existência dominada pelo Estado burocrático, vigilante e controlador, e pela mercantilização da cultura e de todas as esferas da vida. Espaços vazios, incertezas e tartamudeações são táticas praticadas e expressas nos mapas situacionistas que questionam a ordem e estabelecem novas ligações no espaço urbano racionalizado e imposto pelas estratégias ${ }^{14}$.

A cartografia situacionista foi uma tentativa radical no sentido de romper com os dispositivos existentes e transformar a prática urbana em práxis cotidiana e

\footnotetext{
${ }^{14}$ Michel De Certeau define estratégia como práticas utilizadas pela ordem dominante ou sancionadas por forças dominantes que se manifestam em locais de operação e de produção. São frequentemente inflexíveis por se utilizarem de grandes aportes de investimentos de espaço/tempo e dinheiro e seu modo de operar é determinado a partir da estrutura dominante. A tática, por sua vez, é uma expressão de indivíduos ou grupos fragmentados tanto temporal quanto espacialmente, os chamados usuários. O objetivo das táticas é transformar as coisas em algo habitável, em lugares de pertencimento, preenchendo os vazios da estratégia.
} 
universal, experimentada por todos mediante novas subjetivações ${ }^{15}$, pensamento crítico e situações permanentemente renovadas, não comandadas por forças remotas e hierarquizadas.

\section{UMA CARTOGRAFIA RIZOMÁTICA DOS AGENCIAMENTOS}

Para Gilles Deleuze e Félix Guattari o mapa é uma “máquina abstrata”, definida por funções e matérias nas quais forma e função não se distinguem. Sua perspectiva é rizomática, é a de religar as múltiplas práticas microbianas em rizoma, à micropolítica de campos sociais, e produzir novas formas narrativas, transcendendo o modelo dualista árvore-raiz para um modelo em que todos os pontos podem se conectar, inclusive via traços muito diferentes.

Diagramas, mais do que mapas, são uma cartografia das multiplicidades, das articulações de forças, relações de poder, agenciamentos. Construídos a partir do rizoma, quebram a lógica vertical e disciplinadora que orienta os dispositivos e a ordem racional dominante. Desdobram-se horizontalmente e se opõem à lógica unitária e universalista com suas múltiplas direções, dimensões e heterogeneidades conectadas em rede e territorializadas.

[...] o rizoma se refere a um mapa que deve ser produzido, construído, sempre desmontável, conectável, reversível, modificável, com múltiplas entradas e saídas, com suas linhas de fuga. [...] Contra os sistemas centrados (e mesmo policentrados), de comunicação hierárquica e ligações preestabelecidas, o rizoma é um sistema a-centrado não hierárquico, não significante, sem General, sem memória organizadora ou autômato central, unicamente definido por uma circulação dos estados. [...] Um platô está sempre no meio, nem início nem fim. Um rizoma é feito de platôs. (DELEUZE; GUATTARI, 1995, p.32).

No mesmo sentido da subversão e transcendência do mapa tradicional, Guattari (1992) defende uma cartografia da cidade que articule política e subjetividade na constituição de uma cidade dialética, criada não apenas por especialistas, mas por todos os seus componentes. Dispositivo que engendra a

\footnotetext{
${ }^{15}$ Subjetivações não engendradas pelos dispositivos, mas criadas em uma prática livre das imposições verticais dominantes.
} 
existência humana, suas subjetividades individuais e coletivas, por meio de materialidades e imaterialidades, o estudo da cidade é crucial, visto que até meados do século XXI estima-se que pelo menos $80 \%$ das pessoas viverão em áreas urbanas.

Para Guattari o ser humano contemporâneo é desterritorializado, porque a realidade está dispersa em universos incorporais, sem lugar determinado na terra e em permanente circulação ao redor do globo. É preciso reconstruir uma relação particular com o cosmo e com a vida, recompor a singularidade individual e coletiva de cada um.

A cidade dialética, diversamente da cidade ordenada por poderes verticalizados, definidos pelo mercado, é uma cidade em constante movimento, mediante uma cartografia multidimensional, subjetiva praticada por todos e ligada rizomaticamente. Demanda-se, neste caso, uma apreensão 'transversalista' da subjetividade, que articule pontos de singularidade (configurações particulares, dimensões existenciais específicas, entre outras).

Neste sentido, um mapa diagrama seria uma cartografia da cidade subjetiva e, como tal, um contra-dispositivo cartográfico.

\section{UMA CARTOGRAFIA DO LEVANTE}

O objetivo de minha investigação de pós-doutorado, que está em andamento, é explorar ações e narrativas da cidade geradas a partir dos percursos cotidianos de variados grupos sociais e da pesquisadora, em cruzamentos e superposições com análises sobre materialidades e histórias da cidade. A escolha dos grupos selecionados recai, em tempos de concentração cada vez maior de renda e precarização do trabalho, sobre coletividades menos inseridas no sistema, menos visíveis, frequentemente silenciadas e socialmente desvalorizadas.

Capturadas durante minhas caminhadas ou percursos motorizados pela cidade, as fotos aqui apresentadas problematizam o desequilíbrio social que se 
verifica em não poucos lugares de São Paulo. Apresentam territórios nos quais a pobreza, por falta de opção, precariamente se fixou, contrastando com materialidades e fluxos que ali ocorrem.

A investigação se iniciou em 2019 com minhas experiências práticas em percursos semanais para a faculdade em que leciono, próxima à Estação Marechal Deodoro, cuja saída fica em frente ao Minhocão. Como as aulas são no período noturno, o trajeto de cerca de 500 metros entre o metrô e a faculdade é coberto no lusco-fusco da hora crepuscular e na volta na escuridão da noite.

Como se sabe, os baixos do Minhocão, na Rua Amaral Gurgel, costumam ser ocupados por aqueles que não têm lugar dormir, entre outras razões porque são sem-teto ou porque não têm dinheiro para pagar a passagem de transporte coletivo no trajeto casa-trabalho-casa. Ocupam também as calçadas da avenida, deitando-se sob as marquises dos prédios que avançam sobre o passeio. O cenário é desolador, e o número de cidadãos sem cidadania aumenta cada dia mais com a crise do capitalismo e da globalização, que aprofunda cada vez mais o abismo entre ricos e pobres. Este foi o primeiro tema a se descortinar para o trabalho.

Como registrar essa realidade sem invadir a já exígua privacidade daqueles indivíduos? Como obter mais do que fotos embelezadas ou mitificadas da pobreza? Como fazer imagens capazes de contar o incômodo da visão da miséria e fazer das imagens um ato político?

O encaminhamento foi inspirado em magistral análise de Didi-Huberman, entre as quais em "Cascas", de fotos feitas por um prisioneiro judeu de Auschwitz-Birkenau obrigado a participar do Sonderkommando ${ }^{16}$ para ajudar

\footnotetext{
${ }^{16}$ Os Sonderkommandos eram unidades de trabalho compostas por prisioneiros, geralmente judeus, nos campos de concentração nazistas. Os prisioneiros, recrutados entre os recém chegados, eram ameaçados de morte e obrigados a guiar prisioneiros para a câmara de gás, remover e cremar os corpos, localizar obturações de ouro e objetos de valor escondidos nos cadáveres, entre outras tarefas. Depois de um tempo, porém, eram também executados. (NATARAJAN, 2020).
} 
os nazistas a cremar corpos de judeus e de outros prisioneiros executados na câmara de gás. Escondido atrás de um anteparo, o rebelde faz fotos furtivas que contam, em seu enquadramento oblíquo, o ato insurgente operado pelo "fotógrafo clandestino" (DIDI-HUBERMAN, 2017, p. 48) para registrar tal atrocidade. As imagens, expostas por Georges Didi-Huberman na exposição “Levantes" “7 , exibem as rugosidades e irregularidades das imagens e do ato que as conformou.

Escolho não parar para enquadrar nada, aproveito o movimento e tento mirar no que me chama a atenção. Registro, em fotos desfocadas, o passar descuidado dos pedestres nas calçadas ou na estação, deslocando-se com naturalidade diante de uma imagem para lá de absurda. Registro o lixo que se confunde com as pessoas, a racionalidade do desenho geométrico do piso que contrasta com o amontoado de panos, papelões e cobertores nos quais às vezes se vislumbra um pé, um nariz, um corpo, um saco de lixo, objetos coloridos.

Decido usar essa tática em outros deslocamentos que realizo durante a semana: perto da Praça da República, onde acompanho uma reforma, em meu trajeto de volta para casa, dentro do carro, evitando o transporte coletivo por causa do coronavírus. Cada uma tem sua história e em todas elas percebem-se movimentos e paradas, presenças e ausências, contrastes e coincidências. Embora não constituam uma cartografia, as fotos são parte fundamental do trabalho cartográfico do levante que será um dos resultados, na etapa final da pesquisa.

\footnotetext{
${ }^{17}$ Exibida no SESC-Pinheiros (Serviço Social do Comércio) de 19 de outubro de 2017 a 28 de janeiro de 2019.
} 


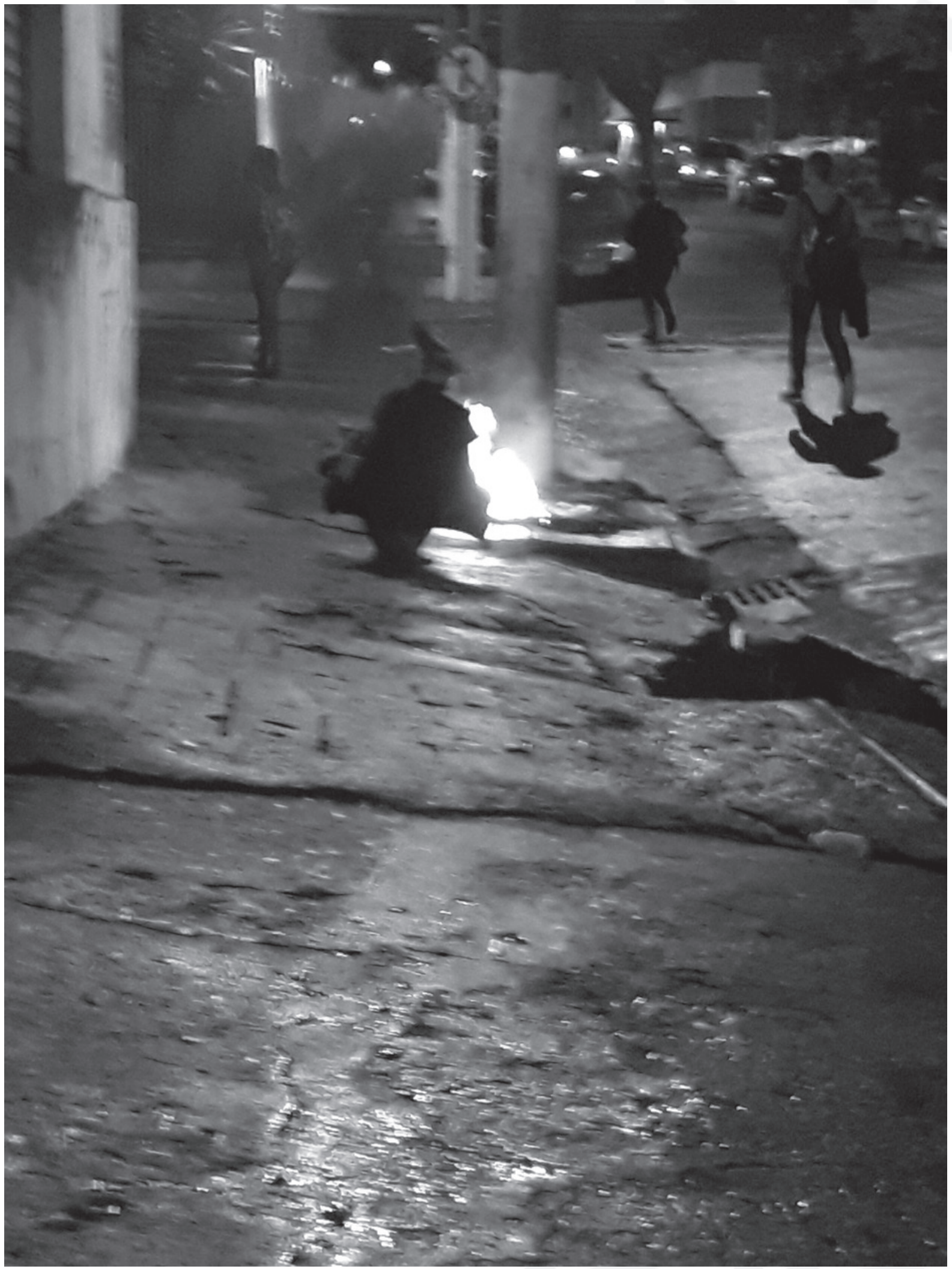




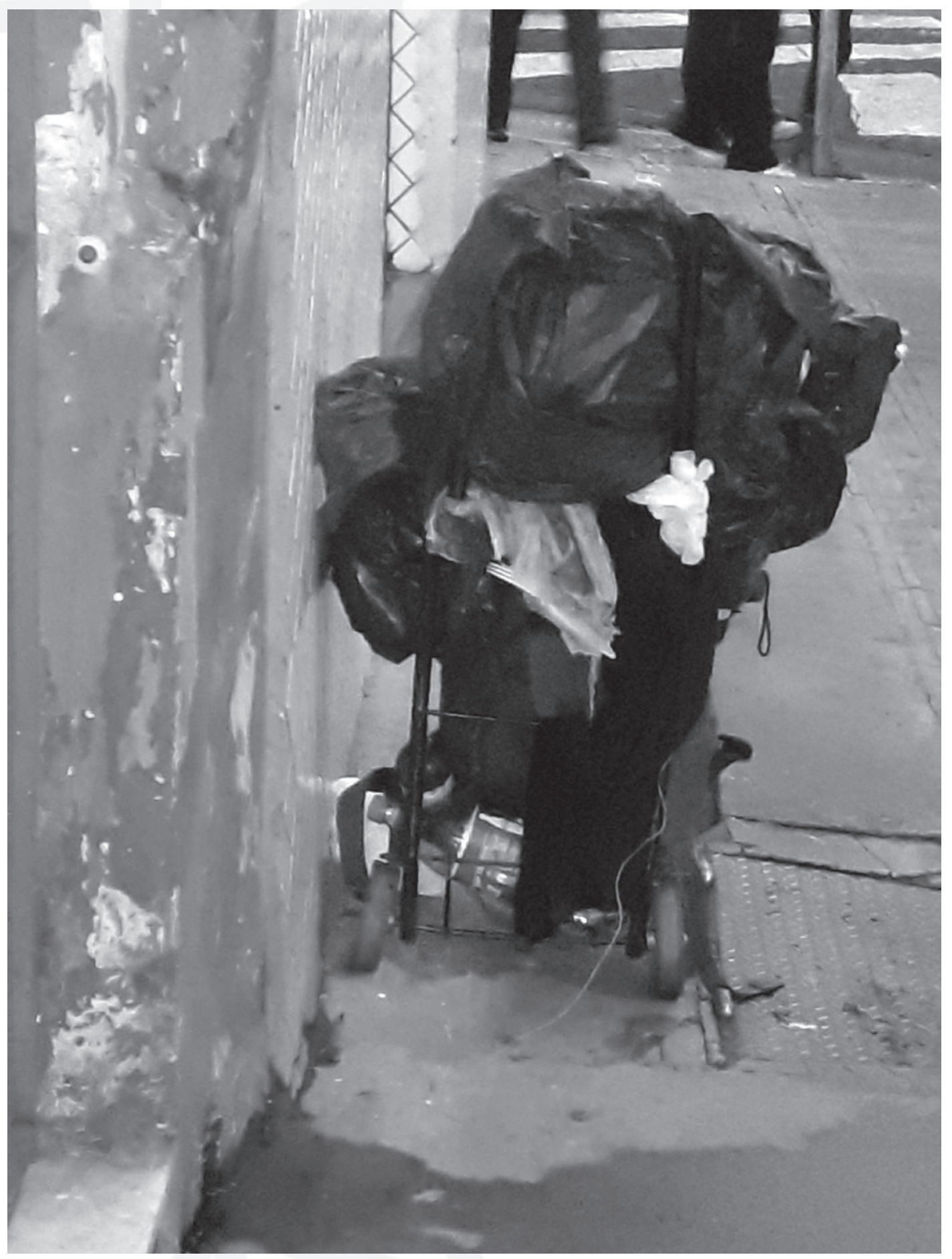




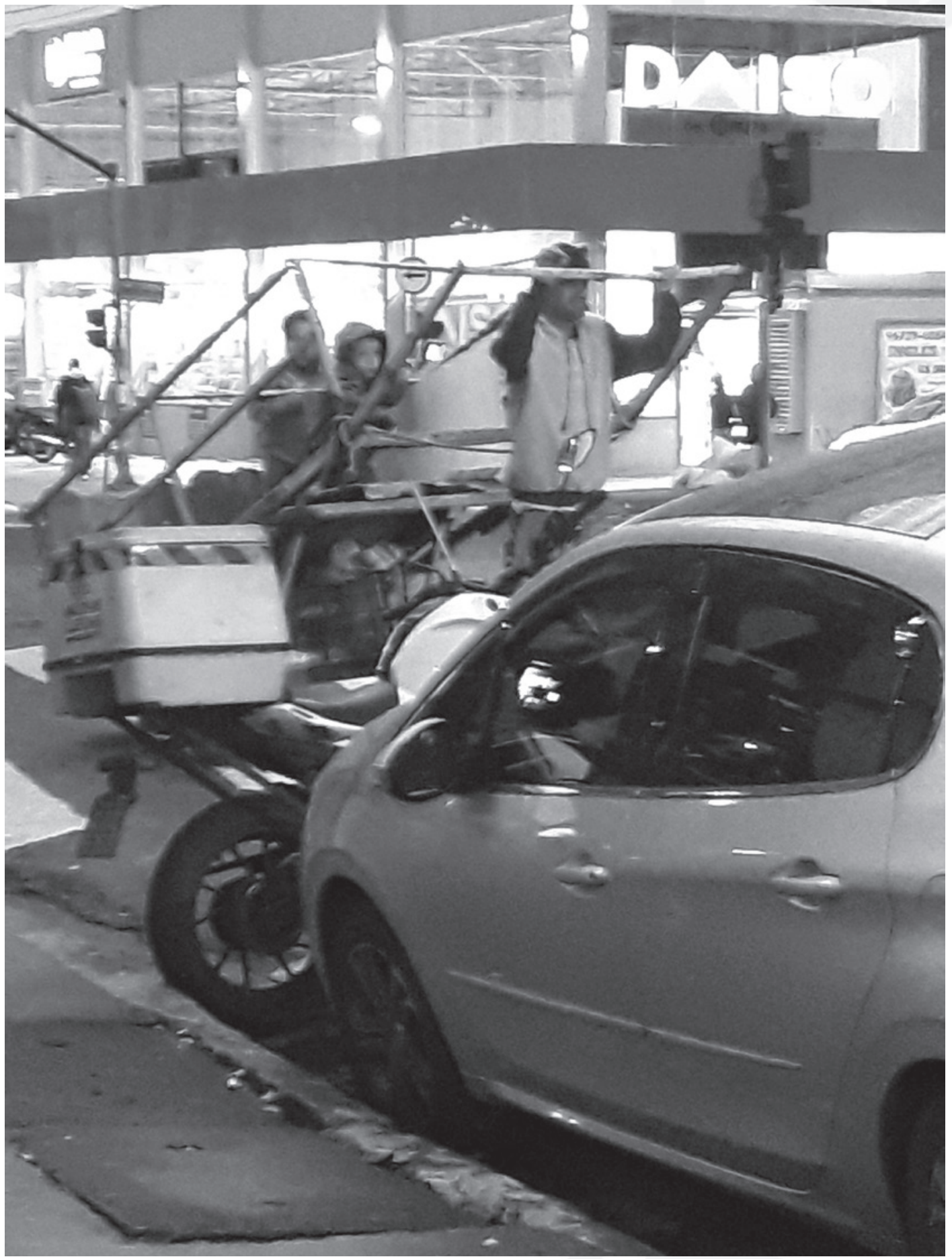



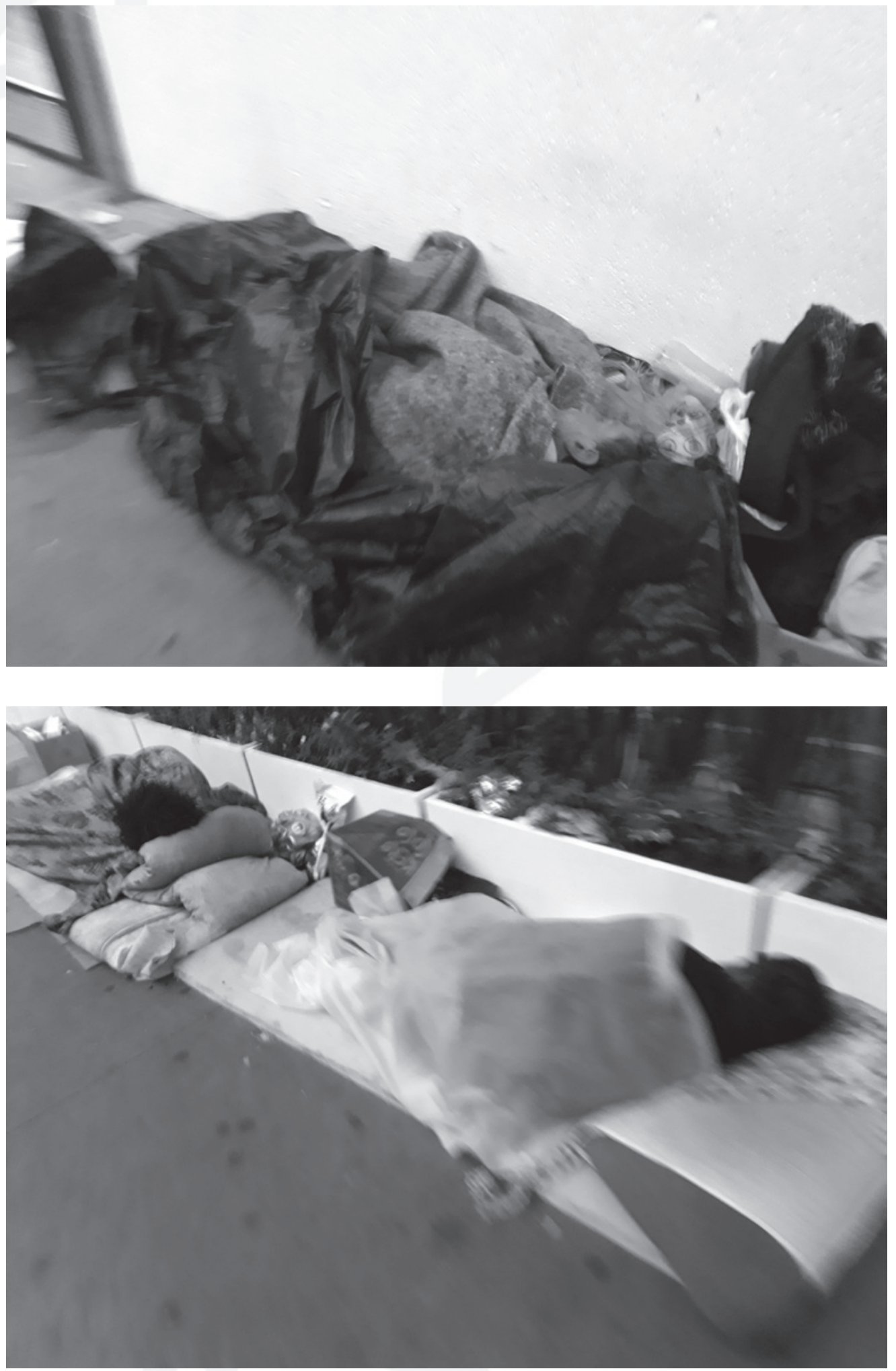


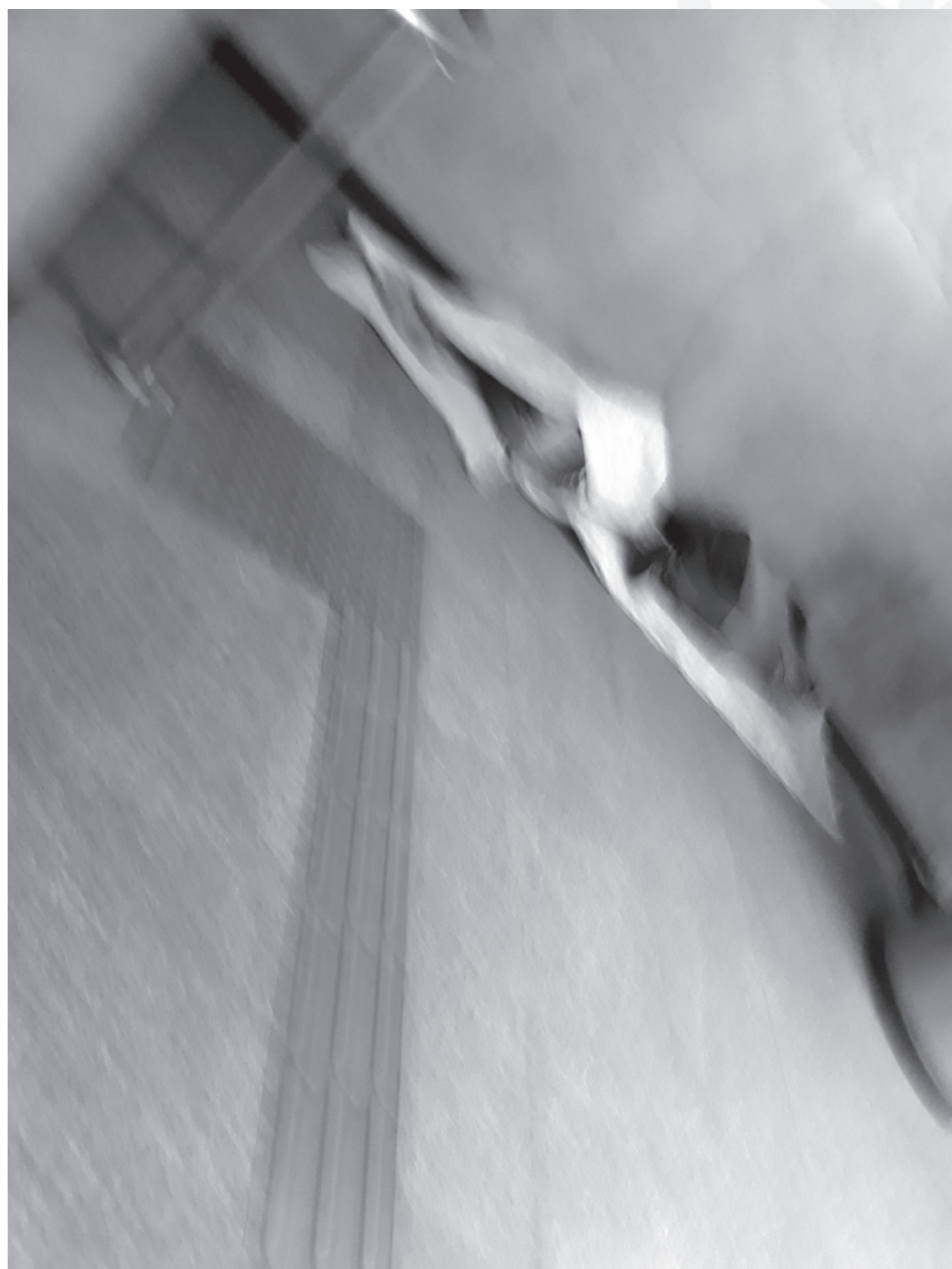



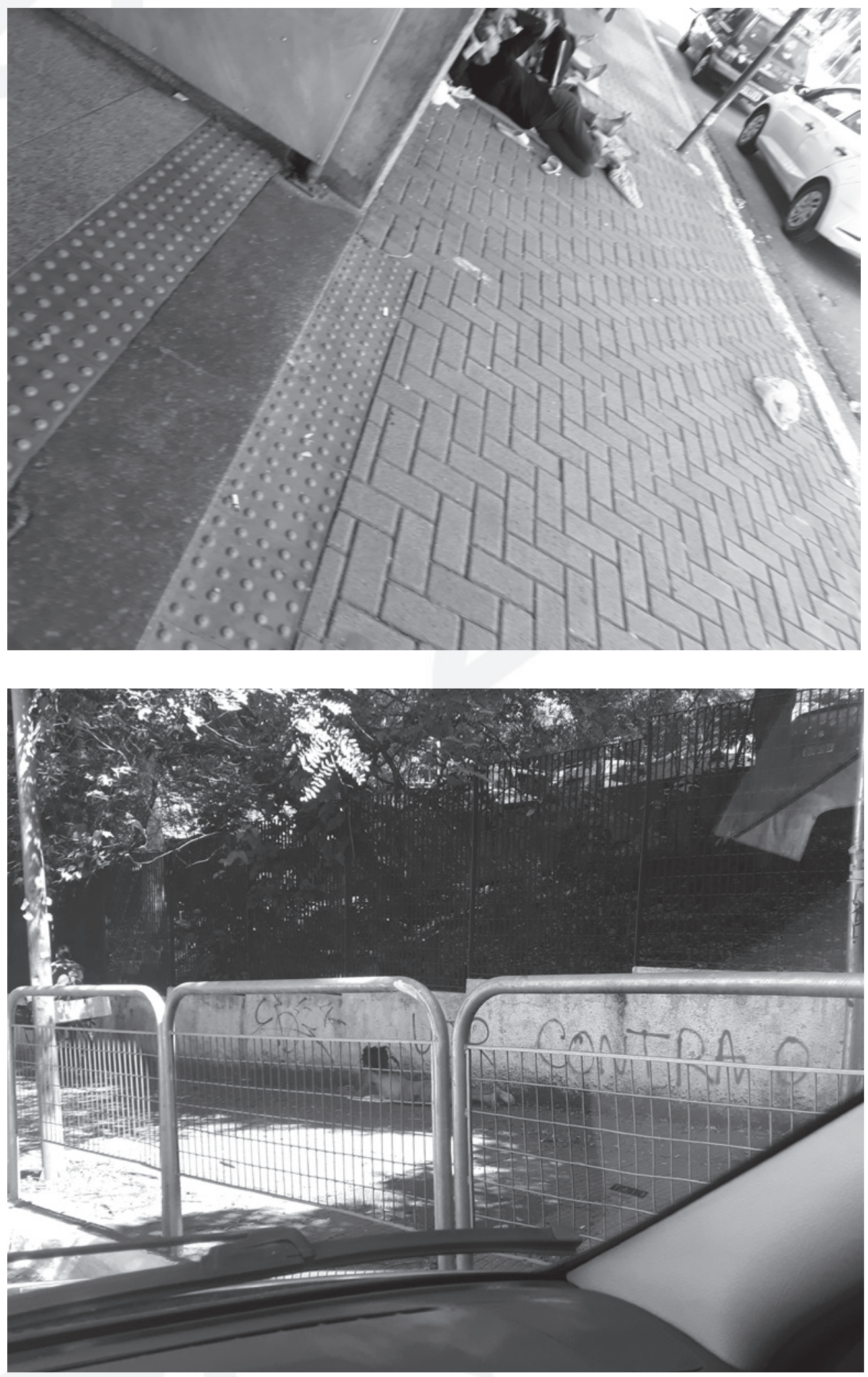


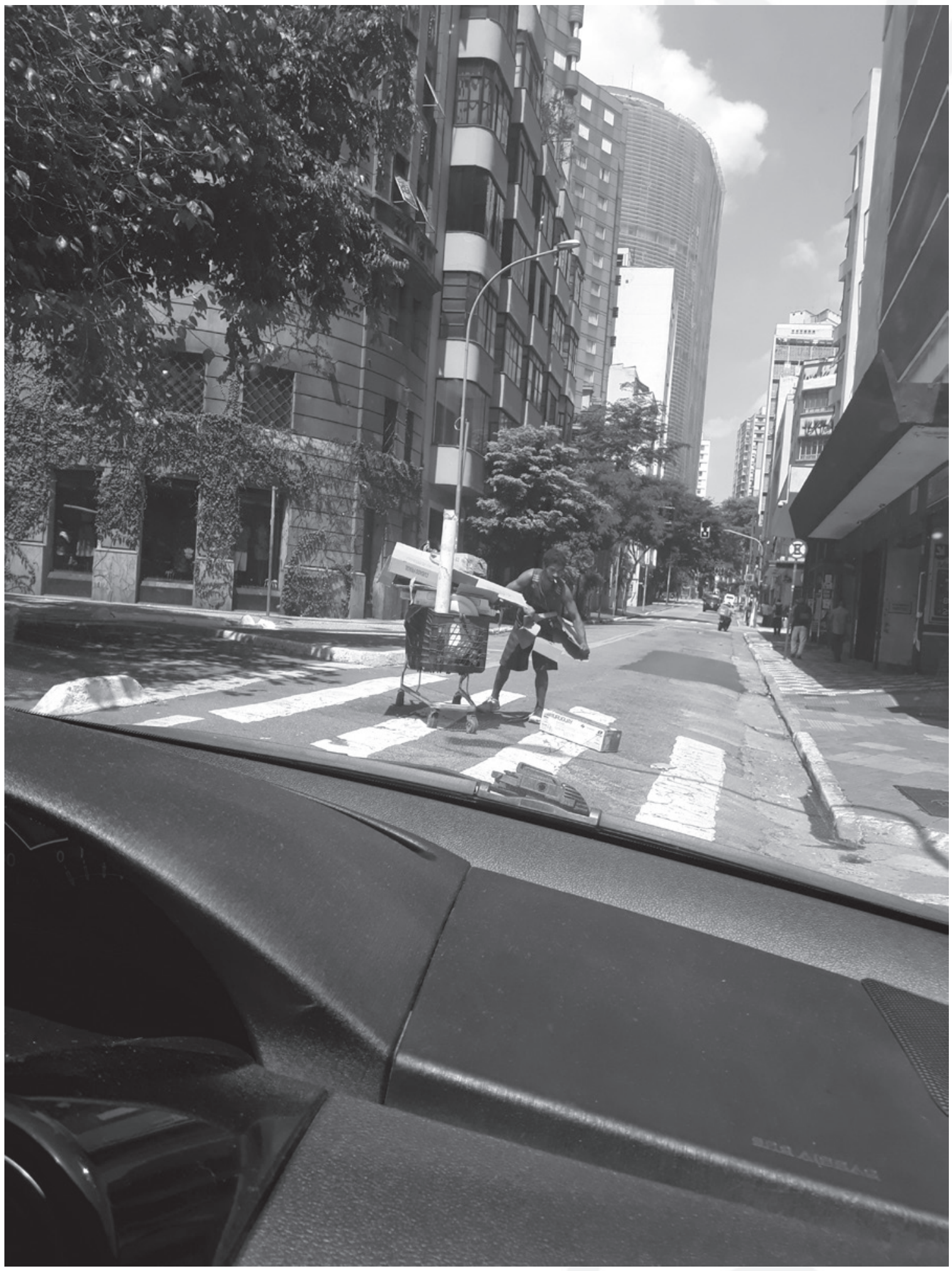

Fotos da autora, São Paulo, 2020. 


\section{CONCLUSÃO}

O mapeamento dos deslocamentos, ritmos, interrupções e percepções subjetivas, observadas à luz da investigação arqueológica dos fatos e materialidades que a cidade expõe ou dissimula, terá espírito insurrecto, uma vez que surge do incômodo e da não-aceitação da ordem vigente, dentro de uma metodologia investigativa, que privilegia debater urbanismo sem urbanidade. Neste sentido, apresenta-se como uma cartografia do levante. Um levantar-se contra imposições, contra narrativas consolidadas, contra desigualdades e injustiças. Um levante que poderá ser notado - às vezes como um rastro atenuado - nas práticas dos grupos investigados ou praticado no ato de pesquisar, em momentos de coleta de imagens e espacialidades que comporão essa cartografia.

Uma cartografia do levante deve ser uma profanação ${ }^{18}$ do mapeamento tradicional, historicamente servindo ao poder dominante. Reivindicada por sujeitos discursivos sistematicamente marginalizados, desconsiderados e penalizados pela ordem vigente, uma cartografia insurgente operaria como um contra-dispositivo, voltada para subjetividades minoritárias e invisibilizadas, subvertendo o controle e a ordenação imposta verticalmente por poderes remotos centrais ${ }^{19}$.

Ao juntar subjetividades e imaginários de diferentes grupos, experiência da pesquisadora, materialidades da cidade e seres sociais invisibilizados, a investigação apresenta sua face rizomática. Conectam-se pontas aparentemente irregulares ou muito distantes de uma existência social fragmentada e apartada de pessoas e territórios, controlada e homogeneizada em sua subjetividade e expressão.

\footnotetext{
${ }^{18}$ Profanação, para Giorgio Agamben (2009), é um gesto de reunião daquilo que foi separado do uso comum dos homens pelos dispositivos. A profanação, portanto, "é um contra-dispositivo que restitui ao uso comum o que foi separado e dividido" pelos dispositivos inseridos nos mecanismos dos jogos de poder (p.45).

19 Referência de Milton Santos (2017) aos poderes dominantes que, em época de globalização, encontram-se remotamente dispersos pelo globo terrestre.
} 
Instituições financeiras, tráfego de automóveis e caminhadas de pedestres se entrechocam nesses territórios, enquanto procuram ignorar a pobreza. Nesses pontos ficam expostas, como fraturas, as contradições do modo de produção que engendra a cidade.

A organicidade dos andrajos, dos papelões e cobertores que servem de casa para aqueles não-cidadãos contradiz a lógica estrita, geométrica e serial dos pisos sobre os quais eles se deitam. O fixar-se no meio da calçada, do passeio, é uma mensagem eloquente de que aquela miséria ficará no caminho dos passantes, interromperá o fluxo dos automóveis, interceptará a respiração.

Ficará no caminho porque ele foi trilhado, ao longo da história, sobre a miséria, o abandono e a marginalização de homens e mulheres cujas vidas não valem quase nada para o corpo social. Refletir sobre o direito à cidade leva a pensar, sobretudo neste caso, no direito à vida que se tem, quem o define e como. Em tempos de pandemia é evidente que essa é uma das populações mais vulneráveis à doença e à morte, porque está em contato com milhares de pessoas que passam pela rua, sem acesso à higiene ou hospitais. A cena remete, inevitavelmente, à ideia de uma necropolítica ${ }^{20}$ de extermínio dos indesejados para o poder constituído.

Uma cartografia do levante é um gesto a favor da vida, contra essa política da morte!

\section{BIBLIOGRAFIA CITADA}

BARBOSA, Ana Gabriela Leirias. Criações poético-espaciais: cartografias e práticas artísticas contemporâneas, 2014. Dissertação (Mestrado em Artes Visuais). Escola de Comunicações e Artes, Universidade de São Paulo, São Paulo.

\footnotetext{
${ }^{20}$ Termo cunhado por Achille Mbembe (2016) para designar o poder soberano daqueles que ditam quem pode viver e quem deve morrer.
} 
BOURDIEU, Pierre. Espaço físico, espaço social e espaço físico apropriado. In: Estudos Avançados, vol. 27, no 79, Instituto de Estudos Avançados, 2013. P133-144.

CERTEAU, Michel de. A invenção do cotidiano - Vol. 1 Artes de fazer. Petrópolis: Vozes, 2014.

CHARTIER, Roger. A história cultural: Entre práticas e representações. Lisboa: Difel/ Rio de Janeiro: Bertrand Brasil, 1990.

DELEUZE, Gilles; GUATTARI, Félix. Mil platôs. Vol.1. São Paulo: 34, 1995.

DIDI-HUBERMAN, Georges. Cascas. São Paulo: 34, 2017.

FOUCAULT, Michel. Microfísica do poder. Tradução e organização de Roberto Machado. Rio de Janeiro: Graal, 2010.

GUATTARI, Félix. A restauração da cidade subjetiva. In: Caosmose: Um novo paradigma estético. São Paulo: Editora 34, 1992. Tradução de Ana Lúcia de Oliveira e Lúcia Cláudia Leão.

HARLEY, John Brian. A nova história da cartografia. O correio da UNESCO. № 8, ano 19. Brasil, ago. 1991, p.4-9.

HARLEY, John Brian. Mapas, saber e poder. In: GOULD, Peter e BAILLY, Antoine. Le pouvoir des cartes et la cartographie. Paris: Antropos, 1995, p. 19-51. Traduzido por Mônica Balestrin Nunes.

MANIFESTO Internacional situacionista. Internacional Situacionista no 4. 1960.

MBEMBE, Achille. Necropolítica. Revista do ppgav/eba/ufrj no 32, dez. 2016, p. 123-151.

MESQUITA, André Luiz. Mapas dissidentes: Proposições sobre um mundo em crise (1960-2010). 2013.Tese (Doutorado em História Social). Faculdade de Filosofia, Letras e Ciências Humanas, Universidade de São Paulo, São Paulo.

NATARAJAN. Swaminathan. Os chocantes relatos dos Sonderkommandos, judeus forçados a trabalhar nas câmaras de gás do holocausto. $B B C$ News Brasil, 24 jan. 2020. Disponível em:

https://www.bbc.com/portuguese/internacional-51230256 Acesso em: 15 mar. 2020.

SANTOS, Milton. A natureza do espaço: técnica e tempo, razão e emoção. São Paulo: Edusp, 2017. 


\section{LISTA DE FIGURAS}

Figura 1: foto da autora, São Paulo, 2020. - pág.: 160

Figura 2: foto da autora, São Paulo, 2020. - pág.: 161

Figura 3: foto da autora, São Paulo, 2020. - pág.: 162

Figura 4: foto da autora, São Paulo, 2020. - pág.: 163

Figura 5: foto da autora, São Paulo, 2020. - pág.: 163

Figura 6: foto da autora, São Paulo, 2020. - pág.: 164

Figura 7: foto da autora, São Paulo, 2020. - pág. 165

Figura 8: foto da autora, São Paulo, 2020. - pág.: 165

Figura 9: foto da autora, São Paulo, 2020. - pág.: 166 